\title{
Patient satisfaction with nurse practitioner care in Newfoundland and Labrador
}

\author{
Wanda Emberley-Burke*1, Robert J. Meadus ${ }^{2}$, June Creina Twomey ${ }^{2}$, Kelly Power Kean ${ }^{1}$ \\ ${ }^{1}$ Centre for Nursing Studies, Canada \\ ${ }^{2}$ Memorial University School of Nursing, Canada
}

Received: July 5, 2018

DOI: $10.5430 / \mathrm{cns} . v 6 \mathrm{n} 4 \mathrm{p} 101$
Accepted: July 27, 2018

Online Published: August 1, 2018

\begin{abstract}
Objective: The aim of the study was to determine the level of patient satisfaction with health care provided by Nurse Practitioners (NPs) in Newfoundland and Labrador (NL), in primary health care settings.

Methods: This is a descriptive study. 155 adult patients $(\mathrm{N}=155)$ were recruited from the four regional health authorities (RHAs) throughout NL who employed NPs in a primary health care setting. A 47-item questionnaire called the Nurse Practitioner Satisfaction Survey (NPSS) was given to patients after receiving care from a NP.

Results: Over $93 \%$ of the participants agreed or strongly agreed with their degree of satisfaction of care provided by the NP. Patients who visited the NP one to five times in the past year reported higher levels of satisfaction. No significant differences based upon marital status, gender or ethnicity were found.

Conclusions: Patient satisfaction was rated as high for care provided by NPs with over $98 \%$ of participants reporting they would seek the services of a NP in the future. The majority of the participants would recommend the NP to others seeking health care services. This study describes patient satisfaction with NP care and highlights NPs as valued providers of care in rural and urban primary health care settings. Identified narrative themes were timely access to care, NP knowledge, trust, and provider consistency. NPs should seek ways to ensure they work to their full scope of practice to meet the needs of the population and increase their presence in primary health care settings.
\end{abstract}

Key Words: Nurse practitioner, Patient satisfaction, Primary health care, Research, Survey

\section{INTRODUCTION}

We are living in a climate where there are increased health care demands on an already congested health care system. Statistics Canada reports that $40 \%$ of the total population are living longer with 5 or more co-morbidities and $60 \%$ of the population 70 and older are still living in their own homes. ${ }^{[1]}$ However access to a health care provider in a timely manner is a challenge. Newfoundland and Labrador (NL), from a geographical perspective, has many obstacles to meet the health needs of the province. Rural and remote communities require that individuals must travel great distances to receive access to health services and therefore at a greater cost to the health system. This along with an aging population, an increase in chronic diseases within the general population and difficulty in recruitment and retention of health professionals, specific to rural regions, contributes to the timely access problem. Nurse Practitioners (NPs) utilized to their full scope of practice, as an effective health resource, at a point of care that is close to the patient's community can contribute to lessening Canada.

Published by Sciedu Press 
the overall burden on health care costs.

Capitalizing on health care professionals who meet the diverse health needs of a population is a way to ensure optimal well-being is achieved. Equally it is important to know whether or not patients feel that their needs are being met. Collectively this knowledge can be an impetus to explore if the care delivered by NPs, as a viable sustainable solution to alleviate health care system strain, is valued by patients. Health care services that can be provided within the community should be evaluated from the patient's opinion. ${ }^{[1]}$

Patient satisfaction, a subjective response to the patienthealth care provider encounter, is a reflection of perceptions and values that the individual places on the quality of care and the experience of care received during the face to face health meeting. ${ }^{[2,3]}$ The literature reports positively on patient satisfaction with NP delivered care and satisfaction with care which leads to good health outcomes for the overall community or population. ${ }^{[3,4]}$ However, research specifically related to patient satisfaction with NP care within the province of NL was absent. The purpose of this research study is to determine the level of patient satisfaction with health care delivery by NPs in NL primary health care clinics. The outcomes of the research will contribute to the existing literature on patient satisfaction of NP delivered health care.

The study was conducted at all primary health care clinics in the four NL regional health authorities (RHAs) where NPs were employed. A primary health care clinic is a health service that is provided through a community designated health centre or an outpatient clinic or whereas otherwise defined by the RHA (see Figure 1).

\subsection{Literature reviews}

Research on patient satisfaction links the perceived experience by the patient, and the encounter with the health care provider, to the actual service received and the expectation of that service. ${ }^{[2,3]}$ The term patient satisfaction has been widely debated and several definitions exist. However, the meaning of the quality of patient satisfaction experiences remains elusive ${ }^{[5]}$ considering that self-rated health is independent of demographics and health risk behaviours. ${ }^{[6]}$ Patient satisfaction does have statistical value as a marker of quality care, but is continuously changing. ${ }^{[7,8]}$ Patient intrinsic motivation, patient satisfaction, and the link to nursing action continue to be undetermined. Multiple elements including demographics, previous health care experiences, value systems, social resources, environmental factors and the individuals interface with the health care system, all contribute to ultimate patient satisfaction with the health care provider. ${ }^{[3,4]}$

Simply put patient satisfaction is determined by how well the patient is affected by the care they received.

Patient satisfaction was evaluated with clinic services at the Sudbury District Nurse Practitioner Clinic (SDNPC) in Ontario, Canada. Participants rated their overall level of satisfaction as satisfied or very satisfied with NP care. Most notably, satisfaction with lifestyle counselling in the management of chronic disease was significantly higher and resulted in positive behavioral outcomes. Statistical significant results were reported related to the demographic of age and accessibility of NP service delivery. The youngest and oldest age groups rated accessibility as low on the level of satisfaction. Immediacy for same day appointment scheduling, misunderstanding of the interprofessional model of care for the younger age group and complex health issues in the older age group limiting their health management contributed to these findings. These researchers did not account for the relationship between perceptions of timely access and management of acute and complex medical conditions. ${ }^{[9]}$

Similarly in a rural Canadian primary health care study, overall high patient satisfaction with NP care was reported. Analysis of transcribed interviews revealed NP knowledge; quality of time spent; attentiveness to care and mutual respect and trust as the base of the collaborative NP patient relationship. Barriers were cited as public lack of knowledge of the NP role and health funding for NP remuneration, while flexible appointment times and access to care were reported facilitators. ${ }^{[10]}$ Qualitative studies have focused on the NP role and relationships with the primary caregiver. The relationship with the primary health provider was reported as having the greatest significance to patient satisfaction with respect and trust reported as significant factors. ${ }^{[10-12]}$

Several studies in Australia, United Kingdom, United States and Canada ${ }^{[13-19]}$ reported that patients are satisfied with the care received from NPs. The authors cite satisfaction related to NP communication increased especially when education was provided on disease prevention, health promotion and chronic disease management. Patient trust with NP expertise and satisfaction with care were reported as very high in relation to accessibility, flexibility, immediacy of NP services. The time afforded by the NP to additional factors of patients' lives ${ }^{[13,14,19]}$ that impacted on the initial health issue, minimized the need for further patient visits.

A Canadian study reported ${ }^{[20]}$ statistical significance in the area of chronic disease management and collaborative practice team building. Additionally, awareness of the NP role, strong physician and health authority support, and the knowledge and philosophical approach of the NP contributed improved quality of health care delivery to the practice population. 


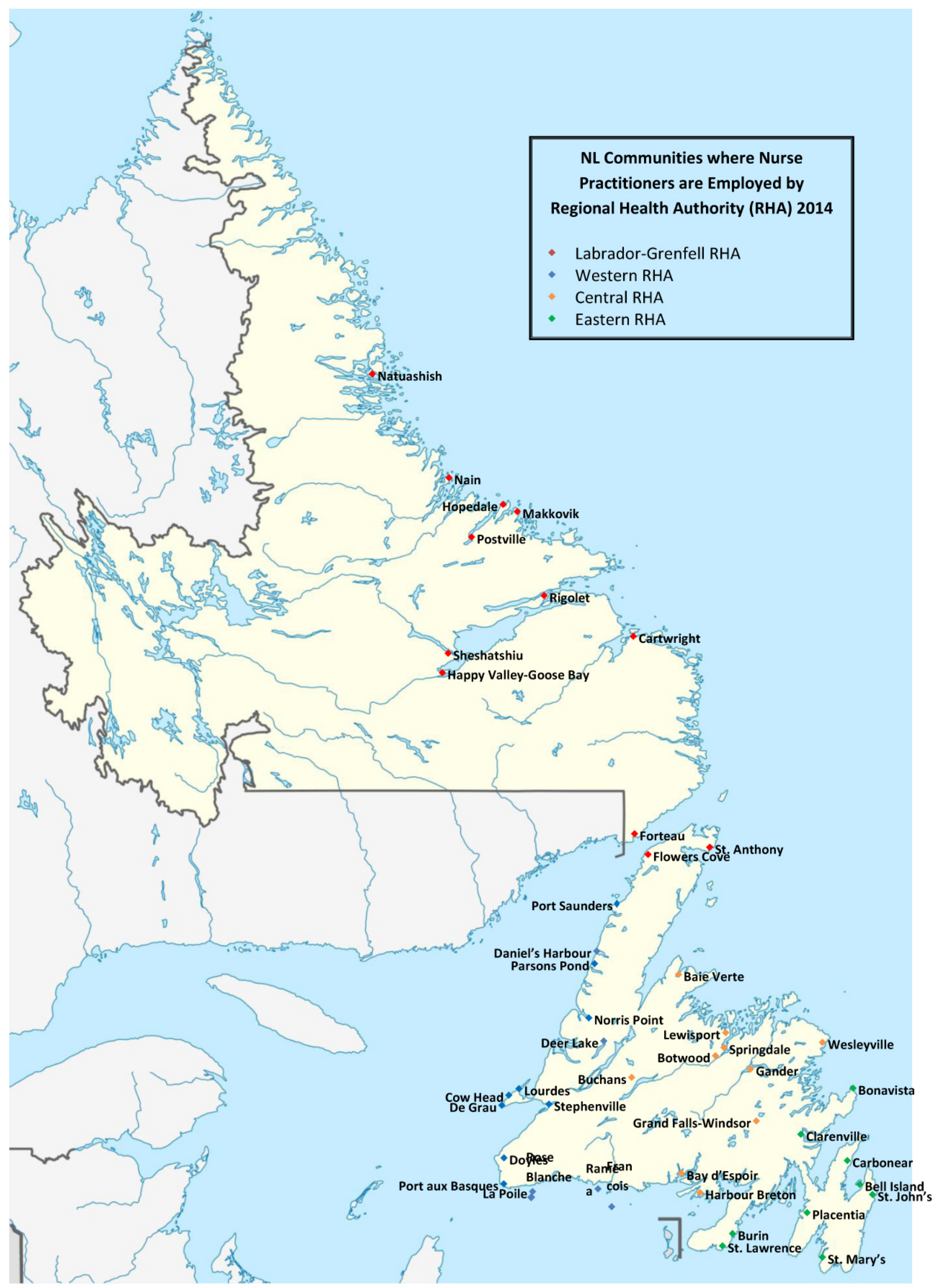

Figure 1. Primary health care clinic locations where NPs are employed 
Additional research from Canada concluded experiences with primary health care teams improved patients' perception of the health care process. Outcome indicators specifically associated with quality of care, coordination of care, patient centeredness, after hour's accessibility and confidence in the system, patient satisfaction generally improved. ${ }^{[21]}$

NP research and patient satisfaction is influenced by NPpatient communication, NP knowledge and access to care and overall, studies related to factors influencing patient satisfaction with NP-provided care found that patients are satisfied. ${ }^{[3,4,12,18,21,22]}$ The literature generally reports that satisfaction with NP care leads to good health outcomes. ${ }^{[3,4]}$

However, research specifically related to patient satisfaction with NP care within NL was absent. To address this gap in knowledge, we undertook this study to examine patient satisfaction with NP care in primary health care settings in NL.

\subsection{Advanced practice nurse}

Primary health care NPs are registered nurses who have received advanced education and experience through a primary health care education program at the diploma, undergraduate or graduate level. In Canada NPs may work in primary health care settings without being educated in a designated primary health care program. The NP does not work in isolation but is part of an interprofessional team which is central in meeting the health care needs of individuals, families, groups and the communities they service. Factors that affect role implementation are role definition, stakeholder participation and acceptance and recognition within organizations and health care teams. ${ }^{[23-25]}$

Historically in NL NP education began at the diploma level. Presently NP education is at the University graduate level. NPs in NL are regulated by the Association of Registered Nurses of Newfoundland and Labrador (ARNNL). ${ }^{[26,27]}$ Specific provincial ARNNL and national Canadian Nurses Association (CNA), competencies, affirm that NPs can diagnose, prescribe medications, order and interpret laboratory and diagnostic tests in the management of non-urgent, urgent and emergent health care issues. Working within this scope of practice, NPs work independently and collaboratively with physicians and other health care providers in primary health care and acute care settings. ${ }^{[25-29]}$

Currently there are 156 practicing NPs in NL; ${ }^{[26]} 134$ are Family All Ages; 19 Adult and 3 Pediatric. NPs practice in urban centres and rural regions of the province under RHAs. The majority work with the collaborative practice model ${ }^{[27-30]}$ with the exception of three NPs who are in private practice. The unique challenges for NPs who work in this province are geographical boundaries, lack of role clarity and challenges associated with service payment. Rural health centres and medical clinics where a single NP is employed can require travel distance between clinics of over 80 kilometres. NPs travel to smaller communities by boat, air or ski-doo to provide nursing service. The role of the NP is not always understood among the public and other health care providers, creating confusion in understanding their full scope of practice. Service remuneration and alternate health funding models for NP provided service need to be explored in the overburdened health care system.

\section{METHODS}

\subsection{Design}

Using a non-experimental design, patient satisfaction was measured with a modified NP satisfaction instrument. ${ }^{[4]}$ The reliability and validity of this instrument has been established with a Cronbach's alpha of 0.98. Patient satisfaction, with employer-sponsored NP primary health care services, within a specific region in the United States that utilized The Nurse Practitioner Satisfaction Survey (NPSS) was examined. The NPSS consisted of 47 items; 28 -items are rated on a 5-point Likert scale and the remaining 19 items address patient and demographic characteristics. The researchers obtained written permission from the author of the NPSS to utilize and modify this tool for use in this study. The modified instrument was titled Patient Satisfaction with NP Care in NL Survey. The questionnaire contained a 12-item demographic section along with 25 items to assess satisfaction with NP provided care and one open-ended question that allowed respondents to comment on their health care experience. The narrative findings were analysed and reviewed by the lead authors by content analysis resulting in four themes: access to care, knowledgable, trust, and the best thing to happen. The survey instrument did not contain questions that assessed respondents' understanding of the NP role, NP remuneration and role implementation. The authors looked specifically at attributes and dimensions, ${ }^{[4]}$ of patient satisfaction related to NP care and interpersonal communication, trust, accessibility and convenience, NP knowledge and competence. Three Subscale scores of accessibility satisfaction, communication satisfaction, and NP knowledge satisfaction represented patient perception of NP provided care.

The questionnaire was pilot tested for readability, clarity, and content validity by experts and NPs. Ten NPs were randomly selected from the provincial public directory of the ARNNL to participate in this activity. Feedback was received from 8 NPs representing an $80 \%$ response rate. Overall, the NPs agreed that the content of the survey was appropriate, valid and clear. 


\subsection{Population}

A convenience sample of participants, competent to give consent, aged $18-86$ and older $(\mathrm{N}=155)$ who visited a primary health care setting within one of the four RHAs [Eastern, Central, Western, Grenfell Labrador], and seeking care from an NP participated in this study.

Recruitment occurred through advertisements placed within each identified clinic.

\subsection{Procedures}

The receptionist/intermediary within each clinic provided patients, interested in participating, with a questionnaire package which contained an informed consent letter, survey, and postage-paid return envelope. Follow-up procedures to aid sample procurement involved contacting the clinic designates and regional managers of all primary health clinics monthly during the data collection phase to determine if the research package had been received and if more surveys were required. Completing the survey was taken as implied consent to participate in the study. Data were kept in a locked cabinet and accessible only to the researchers.

\subsection{Statistical analysis}

Data were analyzed using the Statistical Package for Social Sciences, Version 22 (SPSS). Descriptive statistics were used to explore the data. Subscales were created, paralleling the NPSS instrument ${ }^{[4]}$ for general satisfaction, communication, accessibility and convenience of scheduling and satisfaction with NP knowledge. Non-parametric statistics were used to determine differences in scores as the data was not normally distributed. The open-ended question on the survey exploring any additional comments about the NP services was examined for similarity of narrative findings using content analysis. The lead authors independently coded words and sentences that were grouped together. The two primary researchers discussed and agreed upon the final themes.

\subsection{Ethics}

Ethical approval was obtained from the NL Health Research Ethics Board, Health Research Review Committee from each RHA, and the First Nations government.

\section{RESULTS}

Seven hundred and eighty questionnaires were distributed to 54 clinics. Eight clinics returned the questionnaires because NP service was unavailable or patient population was deemed inappropriate by the clinic manager. A total of 155 surveys were returned. The majority of participants were female $(76 \%)$ (see Table 1). There was a range of responses from the four regions of the province (see Table 2).
Table 1. Demographics of participants

\begin{tabular}{|c|c|}
\hline Variables & Participants $(\mathrm{N}=155)$ \\
\hline \multicolumn{2}{|l|}{ Age in years } \\
\hline $18-25$ & $3 \%$ \\
\hline $26-35$ & $10 \%$ \\
\hline $36-45$ & $12 \%$ \\
\hline $46-55$ & $25 \%$ \\
\hline $56-65$ & $36 \%$ \\
\hline $66-75$ & $14 \%$ \\
\hline \multicolumn{2}{|l|}{ Ethnic origin } \\
\hline Caucasian & $68 \%$ \\
\hline Innu & $1 \%$ \\
\hline Inuit & $3 \%$ \\
\hline Mi'kmaq & $9 \%$ \\
\hline Other & $9 \%$ \\
\hline Unspecified & $10 \%$ \\
\hline \multicolumn{2}{|l|}{ Gender } \\
\hline Female & $76 \%$ \\
\hline Male & $23 \%$ \\
\hline Unspecified & $1 \%$ \\
\hline \multicolumn{2}{|l|}{ Employment Status } \\
\hline Employed & $48 \%$ \\
\hline Unemployed & $19 \%$ \\
\hline Retired & $31 \%$ \\
\hline Unspecified & $2 \%$ \\
\hline \multicolumn{2}{|l|}{ Education } \\
\hline Less than high school & $2 \%$ \\
\hline High school diploma & $27 \%$ \\
\hline Some vocational/technical school & $21 \%$ \\
\hline Some college university & $20 \%$ \\
\hline Bachelors & $7 \%$ \\
\hline Masters & $3 \%$ \\
\hline \multicolumn{2}{|l|}{ Region of province residing } \\
\hline Eastern & $20 \%$ \\
\hline Labrador & $10 \%$ \\
\hline Central & $17 \%$ \\
\hline Western & $30 \%$ \\
\hline Northern & $23 \%$ \\
\hline
\end{tabular}

Most of the respondents were from the Central, Western, Northern and Labrador regions. Although response rates varied by clinic location, it was interesting to note that the Eastern region reported a low level of response (19.4\%) considering it is the largest health care region and the most populated geographical area in NL. The patients ranged in age from 18 to 55 (46\%), and 56 to 86 years (54\%). Some participants had multiple health concerns and were taking numerous prescribed medications, but these factors did not significantly relate to their level of satisfaction.

Seventy-six percent were of Caucasian ethnicity, highest education level completed was high school level (26.8\%) and at the time of the study (31.6\%) of the participants had full time employment. Seventy-five percent were married, 
and $62 \%$ had health insurance. The predominant health issue reported by participants was hypertension (41.4\%). The response rates varied among the regional clinics: Eastern (19.4\%), Central (17\%), Western (30\%), Northern (23\%) and
Labrador (10\%). No statistical significance was noted in patient satisfaction for the demographic factors: age, gender, ethnicity, and educational level.

Table 2. Regional health authority response rate

\begin{tabular}{lllll}
\hline RHA & Frequency & Percent & Valid Percent & Cumulative Percent \\
\hline Eastern Region & 30 & 19.4 & 19.6 & 19.6 \\
Central Region & 28 & 16.8 & 17.0 & 36.6 \\
Western Region & 46 & 29.7 & 30.1 & 66.7 \\
Northern Region & 36 & 23.2 & 23.5 & 90.2 \\
Labrador & 15 & 9.7 & 9.8 & 100 \\
Missing & 2 & 1.3 & & 100 \\
Total & 155 & 100 & & \\
\hline
\end{tabular}

Table 3. Accessibility subscale satisfaction on the patient satisfaction with NP care in NL Survey

\begin{tabular}{llll}
\hline Accessibility Variable & N & MEAN & SD \\
\hline Schedule appointments with the NP in the future \#3 & 151 & 4.9735 & 4.1999 \\
Convenient appointment time \#5 & 144 & 4.4653 & 1.0371 \\
No difficulty getting NP appointment \#6 & 143 & 4.2657 & 1.1255 \\
Easy access to the health clinic \#7 & 154 & 4.5714 & 0.934 \\
Easier to schedule with NP then regular health provider \#8 & 144 & 4.3264 & 1.0500 \\
Amount of time spent with NP \#13 & 148 & 4.6622 & 0.892 \\
\hline
\end{tabular}

The number of visits was significantly different because of the large difference in population statistics for NL. The level of satisfaction of NP provided care for patients who visited one to five times was higher in the Agree or Strongly agree rating. However, there was an insignificant negative correlation between the number of visits and satisfaction. This finding means that the number of visits isn't positively correlated with satisfaction (Pearson $-1.02, p=.212$ ). Statistically significant results were reported related to the demographic of age and accessibility of NP service delivery (see Table 3 ). The relationship between access to care and management of medical conditions was not examined. Most respondents were from the rural regions and of an older age demographic. This finding was reasonable given the location of the NP clinics and the provincial aging demographic.

For the subscale scores of general satisfaction, communication, and NP knowledge there was no difference by region, age or gender. Accessibility and convenience subscale scores were significantly lower at .014 for women. This finding may have been influenced by the lack of a health care provider or participants needing to be seen at an alternate time, lack of transportation, or child care responsibilities. There were no differences in the other three subscales for gender. There were no differences for the majority of items by region, age or gender on individual item scores. The overall satisfaction of NP-provided care and expertise was high for this sample. Participants rated their overall level of satisfaction as satisfied or very satisfied with NP care. Patient satisfaction was also high for consistency of health care provider, accessibility, flexibility with scheduling and rapport development. NP provided care was sought highest $(n=151,63.3 \%)$ outside the greatest urban populated area of the province, the eastern region. Easier access to health services and location of regional health boundaries may have influenced choice of health care provider selection. Satisfaction with type of health care provider selected was not examined in this study. Patient satisfaction was high for care provided by NPs and over $98 \%$ of participants would seek the services of a NP in the future.

\subsection{Narrative findings}

Eighty (80) participants provided statements on their healthcare experience. The narrative findings were reviewed by the authors resulting in four themes: access to care, knowledgeable, trust, and the best thing to happen. The use of qualitative inquiry aids the researcher in gaining a greater un- 
derstanding of the patient experience and can offer benificial knowledge to NP in the practice setting. ${ }^{[31]}$

\subsubsection{Access to care}

Participants described having a NP in the region in which they resided gave them the option to have their health care needs addressed when the need arose. "Waiting for 3 to 5 days" to see other health professionals was seen as worrisome. They described "the NP is easily available and very much a necessity in the rural region". Access to a health professional for them meant that the care they received would be consistent and reliable. These findings were similar with the literature. ${ }^{[21,32,33]}$

"When answering the questions about scheduling an appointment with the NP, I answered disagree because she works in several clinics in the region and it is very difficult to get an appointment with her. She is stretched over our vast coast providing services rather than being located in one health center. Not enough NP's. Appreciate that she is from the area and language or culture is not a barrier."

"The NP attends to my mother, who is 93, with the utmost care and compassion. Before the NP started to visit my mother, we would be waiting up to two hours in a hospital waiting room for her regular medical appointments. I strongly recommend the NP for the elderly."

\subsubsection{Knowledgeable}

Participants communicated that knowing the NP was wellinformed about their health was very important to them and they considered them a "valuable part of health care". Sensitivity to individual needs and discussion about their acute and chronic diseases supported the particpants' confidence in the health provider relationship. They expressed being in "extremely good hands with the NP" and relief in having "someone of my NP's knowledge to see when needed".

"The Nurse Practitioner is a great service and the NP is an asset to the clinic. She is clear and concise in her presentation of the facts related to my health concerns and offers excellent care."

"Very pleased with the questions she asked me, and how concerned she seemed about me. Took the time to assess me and make sure both me and my unborn baby were ok."

\subsubsection{Trust}

Patricipants expressed gratitude and a level of comfort in knowing that the NP was genuinely concerned about them. The experience of feeling respected and listened to affirmed for them the level of trust which they had gained with the NP from their health visit.

"I am very comfortable talking to the NP and I think this is Published by Sciedu Press very important. Always makes me feel like a person."

"The NP was so much more than I expected. I was very nervous but after I met the NP I relaxed and asked the questions I needed to about my condition and received easy to understand answers. I am glad I went to the NP, talking to someone who actually listened to ME made me feel great about the visit. Thank you."

The themes of trust and knowledge of the NP have been reported in the literature as contributory factors to patient satisfaction and seen as significant to the NP patient relationship. ${ }^{[3,4,9,12-20]}$

\subsubsection{The best thing to happen}

Participants explained that having the NP regularly present increased their confidence in them, in knowing that the NP was familiar with their health problems. Not being "treated like a number" and knowing that the NP was "very well informed about by problems for the last two years" increased their belief that they were "respected" and "any of their health issues" would be addressed at each visit. This theme was a reflection of the relationship that participants had developed with the NP overtime and is consistent with the research. ${ }^{[30]}$ The value that participants placed on needing a consistent health care provider ${ }^{[19,32,33]}$ may have influenced the reposnses in NL.

"Having a NP in our region is a god send. With the large turnover of physicians in our health centre having a consistent NP to go to is a welcomed relief. It sis much easier to seek as I get medical appointments and advice. It was the NP who referred my husband to a specialist and was responsible for his early detection of cancer and perhaps saved his life."

"Very professional, courteous, understanding and caring. Always makes me feel like a person. Very respectful. Always has a smile, very patient goes beyond to find answers. I can reach her anytime during reg. business hours. My highest praise for my NP."

\section{Discussion}

This is the first study to assess patient satisfaction with NP care in primary health care clinics in NL. The findings demonstrate that patients are very satisfied with the care provided by NPs and would recommend this service to others. Overall, care and expertise provided by the NP were rated high for this study. This is consistent with the literature demonstrating that patients were very satisfied with NP health care services. ${ }^{[15,16,21,22,30,32,34-36]}$ Furthermore over $98 \%$ of participants would seek the services of a NP in the future. The findings also indicate that rapport building, accessibility, flexibility with scheduling and consistency of health care provider, 
contributed to patient satisfaction which corresponds with research findings. ${ }^{[20,32]}$ Patient satisfaction for age, gender, educational level and ethnicity had no statistical significance in our study and was also similar to the research. ${ }^{[16]}$ However, age and accessibility of NP services were statistically significant, congruent with research findings on high patient satisfaction with NP care in rural Canadian family practice clinics. ${ }^{[9,34]}$

\section{Limitations of the study}

This study has a number of limitations. The results are based on a convenience sample of patients visiting primary health care settings in one Canadian province and therefore may not be generalizable. The findings however do provide information for NPs in primary health care practice settings.

The length of time a NP was employed in certain clinics may have influenced participation. The longer time a NP was in a community, the more familiar the respondents would be with him/her. Conversely, the shortage of a consistent health care provider, especially in rural settings, may have influenced respondents' participation.

The study did not assess participants' understanding of the NP role and role implementation nor if having a NP present, as a health care provider, was cost effective to the region(s). This knowledge as a stakeholder of health services may have impacted study patient satisfaction rates overall.

The survey response rate $(20 \%)$ was lower than expected. This finding may be related to advertisement posters not being clearly displayed. Some respondents may have taken the survey home with the intent to complete, but did not do so. Additionally, the self-reporting survey may introduce response bias for participants who respond in a socially desirable manner.

A factor that may have hindered sample procurement was the required communication with several levels of management within all four RHAs. Lists of regional clinics was provided to the primary author who made contact with numerous clinic managers informing them of the study and sought their assistance for a clinic intermediary contact. Four clinics were omitted at the initial start of the data collection and several regional clinics no longer employed NPs. Some managers reported the survey was inappropriate based on the clinic client profile. A random sampling of pre-identified clinics may have assured better communication and a greater study response rate.

\section{CONCLUSIONS AND IMPLICATIONS}

This study supports the evidence that patients are very satisfied with the care provided by a NP. NPs must work to their full scope of practice and increase their presence in primary health care settings. NPs are in a pivotal position to assess the needs of primary health care patients in community settings. Patient choice to use NP care and the perception of care received is important in the evaluation of health outcomes and advancing the NP role. ${ }^{[33,36]}$

This study supports the existing research on satisfaction related to health services provided by NPs. Such knowledge may lead to greater development, support and utilization by RHAs of NPs in primary health care settings. The utilization of NPs has the potential to reduce burden on overall health care costs within NL.

Additional research of NP practice in the areas of primary health care, improving health outcomes, increasing access and utilization of primary health care services in regional settings could be explored. The researchers of this study recommend future exploration of patient satisfaction of NP care to other settings, such as long-term care and as service demands increase in the provision of care to the larger community. As a health care resource in NL, NP utilization can increase patient access to wellness programs, thereby improving health attitudes and health literacy. The NP's overall impact on positive health outcomes related to the specific needs of this province, such as chronic disease management could be examined.

\section{ACKNOWLEDGEMENTS}

The authors would also like to thank Patricia Grainger who provided data analysis and statistical expertise and Valda Duke in reviewing and edting this article.

\section{FUNDING}

The authors wish to thank the Association of Registered Nurses of Newfoundland and Labrador (ARNNL) and the Education Research Trust and the Atlantic Region Canadian Association of Schools of Nursing (ARCASN) for providing financial support to undertake this study and publicationof this article.

\section{CONFlicts OF InTEREST Disclosure}

The authors declare they have no conflicts of interest. 


\section{REFERENCES}

[1] Young L. Census 2016: For the 1st time, more seniors than children living in Canada. Global News 2017. Available from: https://globalnews.ca/news/3423047/more-senio rs-than-children-in-canada-2016-census/

[2] Sofaer S, Firminger K. Patient perceptions of the quality of health services. Annual review of Public Health. 2005; 26: 513-559. PMid: 15760300. https://doi.org/10.1146/annurev.publ health.25.050503.153958

[3] Turris S. Unpacking the concept of patient satisfaction: A feminist analysis. Journal of Advanced Nursing. 2005; 50(3): 293-298. PMid: 15811108. https://doi.org/10.1111/j.1365-2648.2005.0 $3392 . x$

[4] Agosta J. Patient satisfaction with nurse-practitioner-delivered primary healthcare services. Journal of the American Academy of Nurse Practitioners. 2009; 21(11): 610-617. PMid: 19900223. https://doi.org/10.1111/j.1745-7599.2009.00449.x

[5] Jennings N, Lee G, Chao K, et al. A survey of patient satisfaction in a metropolitan emergency department: Comparing nurse practitioners and emergency physicians. International Journal of Nursing Practice. 2009; 15(3): 213-218. PMid: 19531080. https: //doi.org/10.1111/j.1440-172X.2009.01746.x

[6] Lemley K, Marks B. Patient satisfaction of young adults in rural clinics: Policy implications for nurse practitioner practice. Policy Politics and Nursing Practice. 2009; 10(2): 143-152. PMid: 19783536. https://doi.org/10.1177/1527154409341882

[7] Rohrer J, Arif A, Denison A, et al. Overall self-rated health as an outcome indicator in primary care. Journal of Evaluation in Clinical Practice. 2007; 13(6): 882-888. https://doi.org/10.1111/j. 1365-2753.2006.00766.x

[8] Wager D, Bear M. Patient satisfaction with nursing care: A concept analysis within a nursing framework. Journal of Advanced Nursing. 2008; 65(3): 692-701. PMid: 19016924. https ://doi.org/10.1 $111 / j .1365-2648.2008 .04866 . x$

[9] Heale R, Pilon R. An exploration of patient satisfaction in a nurse practitioner-led clinic. Canadian Journal of Nursing Leadership. 2012; 25(3): 44-56. https://doi.org/10.12927/cjnl.2012.2 3056

[10] Leipert B, Delaney JW, Forbes D, et al. Canadian rural women's experiences with rural primary health care practitioners. Online Journal of Rural Nursing and Health Care. 2011; 11(1): 37-53.

[11] Ploeg J, Kaasalainen S, McAiney C, et al. Resident and family perceptions of the nurse practitioner role in long term care settings: a qualitative study. BMC Nursing. 2013; 12(24): 1-11. https://doi.org/10.1186/1472-6955-12-24

[12] Van de Ven A. What matters most to patients? Participative provider care and staff courtesy. Patient Experience Journal. 2014; 1(1): 131139.

[13] Desborough J, Forrest L, Parker R. Nurse-led primary healthcare walk-in centres: An integrative literature review. Journal of Advanced Nursing. 2011; 68(2): 248-263. PMid: 21834837. https: //doi.org/10.1111/j.1365-2648.2011.05798.x

[14] Hayes E. Nurse practitioners and managed care: Patient satisfaction and intention to adhere to nurse practitioner plan of care. Journal of American Academy of Nurse Practitioners. 2007; 19(8): 418426. PMid: 17655571. https://doi.org/10.1111/j.1745-7 $599.2007 .00245 . x$

[15] McDevitt J, Melby V. An evaluation of the quality of emergency nurse practitioner services for patients presenting with minor injuries to one rural urgent care centre in the UK: A descriptive study. Journal of Clinical Nursing. 2014; 24; 523-535. PMid: 24891126. https://doi.org/10.1111/jocn.12639
[16] Thrasher C, Purc-Stephenson R. Patient satisfaction with nurse practitioner care in emergency departments in Canada. Journal of the American Academy of Nurse Practitioners. 2008; 20(5): 231-237. PMid 18460162. https://doi.org/10.1111/j.1745-7599.2008.0 $0312 . \mathrm{x}$

[17] Wand T, White K, Patching J, et al. Outcomes from the evaluation of an emergency department-based mental health nurse practitioner outpatient services in Australia. Journal of the American Academy of Nurse Practitioners. 2012; 24(3): 149-159. PMid: 22404793. https://doi.org/10.1111/j.1745-7599.2011.00709.x

[18] William A, Jones M. Patient's assessments of consulting a nurse practitioner: The time factor. Journal of Advance Nursing. 2006; 53(2): 188-195. PMid: 16422717. https ://doi.org/10.1111/j. 1365-2648. 2006.03714.x

[19] Wilson A, Shifaza F. An evaluation of the effectiveness and acceptability of nurse practitioners in an adult emergency department. International Journal of Nursing Practice. 2008; 14(2): 149-156. PMid: 18315828. https://doi.org/10.1111/j.1440-172X.2008.0 0678.x

[20] Lawson B, Dicks D, MacDonald L, et al. Using quality indicators to evaluate an effect of implementing an enhanced collaborative care model among a community, primary healthcare practice population. Canadian Journal of Nursing Leadership. 2012; 25(3): 28-42. PMid: 23010918. https://doi.org/10.12927/cjnl.2013.23057

[21] Jesmin S, Thind A, Sarma S. Does team-based primary health care improve patients' perception of outcomes? Evidence from the 2007-08 Canadian survey of experiences with primary care. Health Policy. 2012; 105(1): 71-83. PMid: 22321527. https : //doi.org/10.1016/j.healthpol.2012.01.008

[22] Maul T, Zaidi A, Kowalski V, et al. Patient preference and perception of care provided by advance nurse practitioners and physicians in outpatient adult congenital clinics. Congenital Heart Disease. 2015; 10(5): 225-229. PMid: 26010340. https://doi.org/10.1111/ chd. 12273

[23] Gagan M, Maybee P. Patient satisfaction with nurse practitioner care in primary care settings. Australian Journal of Advanced Nursing. 2011; 28(4): 12-18.

[24] Curran V. Primary Health Care Transition Fund Collaborative Care: Synthesis Series on Sharing Insights. Health Canada. 2007.

[25] Sangster-Gormley E, Martin-Misener R, Downe-Wamboldt B, et al Factors affecting nurse practitioner role implementation in Canadian practice settings: An integrative review. Journal of Advanced Nursing. 2011; 67(6): 1178-1190. PMid: 21261696. https://doi.or $\mathrm{g} / 10.1111 / \mathrm{j} .1365-2648.2010 .05571 . \mathrm{x}$

[26] ARNNL. Standards for nurse practitioner practice in newfoundland and labrador. St. John's: Association of Registered Nurses of Newfoundland and Labrador; c2013 [cited 2013]. Available from: http://www. arnnl.ca/

[27] ARNNL. Entry level competencies for nurse practitioners in newfoundland and labrador. St. John's: Association of Registered Nurses of Newfoundland and Labrador; c2016 [cited 2016]. Available from: http://www. arnnl.ca/

[28] CNA. Advanced nursing practice: a national framework. Ottawa: Canadian Nurses Association; c2008 [cited 2008]. Available from: https://www.cna-aiic.ca/en/

[29] CNA. Canadian nurse practitioner competency framework. Ottawa: Canadian Nurses Association; c2010 [cited 2010]. Available from: https://www.cna-aiic.ca/en/

[30] DiCenso A, Bryant-Lukosius D. Clinical nurse specialists and nurse practitioners in Canada: A decision support synthesis. Ottawa: Canadian Health Services Research Foundation; 2010. 1-52 p. Avail- 
able from: http://www.cfhi-fcass.ca/Libraries/Commis sioned_Research_Reports/Dicenso_EN_Final.sflb.ashx

[31] Chenail R. How to conduct clinical qualitative research on the patient's experience. The Qualitative Report. 2011; 16(4): 1173-1190. Available from: http://www.nova.edu/ssss/QR/QR16-4/che nail.pdf

[32] Ryan K, Rahman A. Examining factors influencing patient satisfac tion with nurse practitioners in rural urgent care centers. Journal of the American Academy of Nurse Practitioners. 2012; 24(2): 77 81. PMid: 22324862. https://doi.org/10.1111/j.1745-759 9.2011.00688.x

[33] Whittemore R, Alexander N, Muench U. Implementation of a lifestyle program in primary care by nurse practitioners. Journal of the American Academy of Nurse Practitioners. 2010; 22(12): 684-693. PMid: 21129077. https ://doi.org/10.1111/j.1745 $-7599.2010 .00562 . x$

[34] Reay T, Patterson M, Halma L, et al. Introducing a nurse practitioner: Experiences in a rural Alberta family practice clinic. Canadian Journal of Rural Medicine. 2006; 11(2): 101-107. PMid: 16630436.

[35] Forgeron P, Martin-Misener R. Parents' intentions to use pediatric nurse practitioner service in an emergency department. Journal of Advanced Nursing. 2005; 52(3): 231-238. PMid: 16194176 https://doi.org/10.1111/j.1365-2648.2005.03585.x

[36] Klaasen K, Lamont L, Krishnan P. Setting a new standard of care in nursing homes. Canadian Nurse. 2009; 105(9): 24-30. PMid: 19998690. 